\title{
Analysis of mixed-mode fracture in concrete using interface elements and a cohesive crack model
}

\author{
VÍCTOR O GARCÍA-ÁLVAREZ ${ }^{1, *}$, RAVINDRA GETTU ${ }^{2}$ \\ and IGNACIO CAROL ${ }^{3}$
}
${ }^{1}$ E.T.S. Ing. de Caminos, Canales y Puertos de Barcelona, Universitat Politècnica de Catalunya, Calle Jordi Girona 1-3, 08034 Barcelona, Spain
${ }^{2}$ Department of Civil Engineering, Indian Institute of Technology Madras, Chennai 600036, India
${ }^{3}$ Department of Geotechnical Engineering, School of Civil Engineering (E.T.S. Ing. de Caminos, Canales y Puertos de Barcelona, Universitat Politècnica de Catalunya, Calle Jordi Girona 1-3, 08034 Barcelona, Spain
e-mail: vgarcia@ciccp.es; gettu@iitm.ac.in; Ignacio.Carol@upc.edu

\begin{abstract}
The paper presents a model, based on nonlinear fracture mechanics, for analysing crack propagation in quasi-brittle materials, such as concrete. The work is limited to two-dimensions, and therefore, the fracture modes of interest are mode I (pure tension) and mode II (pure shear). The constitutive model has been implemented in the context of the finite element method using interface elements. The fracture is simulated through a discrete crack represented by the interface with a cohesive crack stress-separation relation derived from the model, which is based on a fracture criterion, together with a flow rule and a softening law. The model is used for simulating results from an experimental study on beams with centric and eccentric notches of high and normal strength concretes, and explaining other test results available in the literature.
\end{abstract}

Keywords. Nonlinear fracture mechanics; mixed-mode fracture; cohesive crack model; interface elements; quasi-brittle materials.

\section{Introduction}

The objective of this study is to analyse mixed-mode cracking in quasi-brittle materials, and the paper presents the development of a nonlinear cohesive-crack model; the analysis of the behaviour of notched beams of high and normal strength concrete; and, the modelling of other tests described in the literature. The present model was proposed and developed in detail by García-Álvarez (1997), and is an extension of the model of Carol et al (1997) and similar, in some aspects, to that of López (1999).

*For correspondence 
The model has been implemented in a nonlinear finite element code using the discrete crack approach, which is discussed in detail elsewhere (Ngo \& Scordelis 1967; Rots 1988; Rots \& Blaauwendraad 1989; Carpinteri et al 1989; Bocca et al 1990). The implementation strategy adopted here consists of using interface elements (also known as joint elements) for representing the cracks in the continuum (García-Álvarez 1997; Gerstle \& Xie 1992; García-Álvarez et al 1994; Carol et al 2001), and using an automatic mesh generator for partitioning the domain defined by the continuum and the cracks. This helps overcome the main drawbacks of the discrete crack approach, which are: the continuous change in mesh connectivities, and the need for the crack to pass through a prescribed path between the finite elements. Since the structural response due to crack propagation is often associated with decreasing loads and snap-back, a displacement control method (García-Álvarez 1997; García-Álvarez et al 1994) has been employed in order to obtain stable solutions beyond the peak load.

The model has been used to evaluate non-planar fracture in eccentrically-notched beams, which have been tested in the three-point bend (3PB) configuration. Such cracking has often been considered as mixed-mode failure (Swartz et al 1988; Bocca et al 1991; Mariani \& Perego 2003) though several researchers have showed that, when the crack faces are not confined, the mode II component is negligible or non-existent (Jenq \& Shah 1988; García-Álvarez et al 2000). The objective of the tests performed by the authors, on high- and normal-strength concrete beams, was to assess the relative importance of mode II fracture. The relevant experimental details are given here, with further details being available elsewhere (García-Álvarez 1997; Gettu et al 1998; García-Álvarez et al 1998). The test results were analysed in a posteriori analysis with the cohesive crack model. Additionally, the results of tests performed by Hassanzadeh (1990, 1992), where the cracking is dominated by shear, are also analysed.

\section{Cohesive crack model for mixed-mode fracture}

\subsection{Formulation of the constitutive model}

The toughening of the fracture process zone (FPZ), which occurs in front of a progressing crack, is modelled as closing stresses in non-singular cohesive crack models that generally have the following characteristics:

(i) The behaviour of the intact material follows a linear elastic stress-strain relation.

(ii) The crack propagation or fracture criterion can be expressed in terms of stresses and fracture parameters as

$$
F(\underline{S}, \underline{p})=0
$$

where $\underline{S}$ is the stress vector and $\underline{p}$ is a vector consisting of material parameters, such as tensile strength and fracture energy.

(iii) In a monotonically opening crack, $\underline{S}$ is the cohesive stress field in the FPZ, and a function of the crack opening vector $(\underline{\omega})$ :

$$
\underline{S}=\underline{f}(\underline{\omega}),
$$

where $f$ is the softening function.

As mentioned above, a cohesive crack model for tension-shear (mixed mode I+II) fracture is implemented here within the discrete crack approach, where the discontinuity is modelled in the 
context of the finite element method through interface elements (Gerstle \& Xie 1992; GarcíaÁlvarez et al 1994). The fracture behaviour is simulated through the crack stress-separation relation defined by a fracture criterion $F$, which plays the same role as the yield or loading surface in plasticity and is expressed as (García-Álvarez 1997)

$$
F(\underline{S}, \underline{p})=\tau^{2}+\tan ^{2} \phi(\sigma-\chi)(2 a-\sigma+\chi)=0,
$$

where $\sigma$ and $\tau$ are the normal and shear stresses, $\tan \phi$ represents the angle of friction between the crack faces, and $\chi$ and $a$ are functions of the dissipated energy. Figure 1 represents Eq. (3) in a graphical form. In the case of Mode I, $\chi$ is the cohesive (tensile) stress. For the case of mixedmode fracture, an explicit softening function (as in Eq. (2)) cannot be derived from Eq. (3) and, therefore, implicit stress-separation relations have to be developed in terms of the mode I and mode II components of the energy dissipation.

For the uncracked material, the constitutive law of the interface element is linear elastic, with stiffness coefficients $D_{n}$ (normal to the interface element axis) and $D_{t}$ (along the direction of the interface element axis). These coefficients, theoretically, must be infinite but in practice cannot be too large in order to avoid oscillations in the stress profile (Rots 1988; García-Álvarez et al 1994).

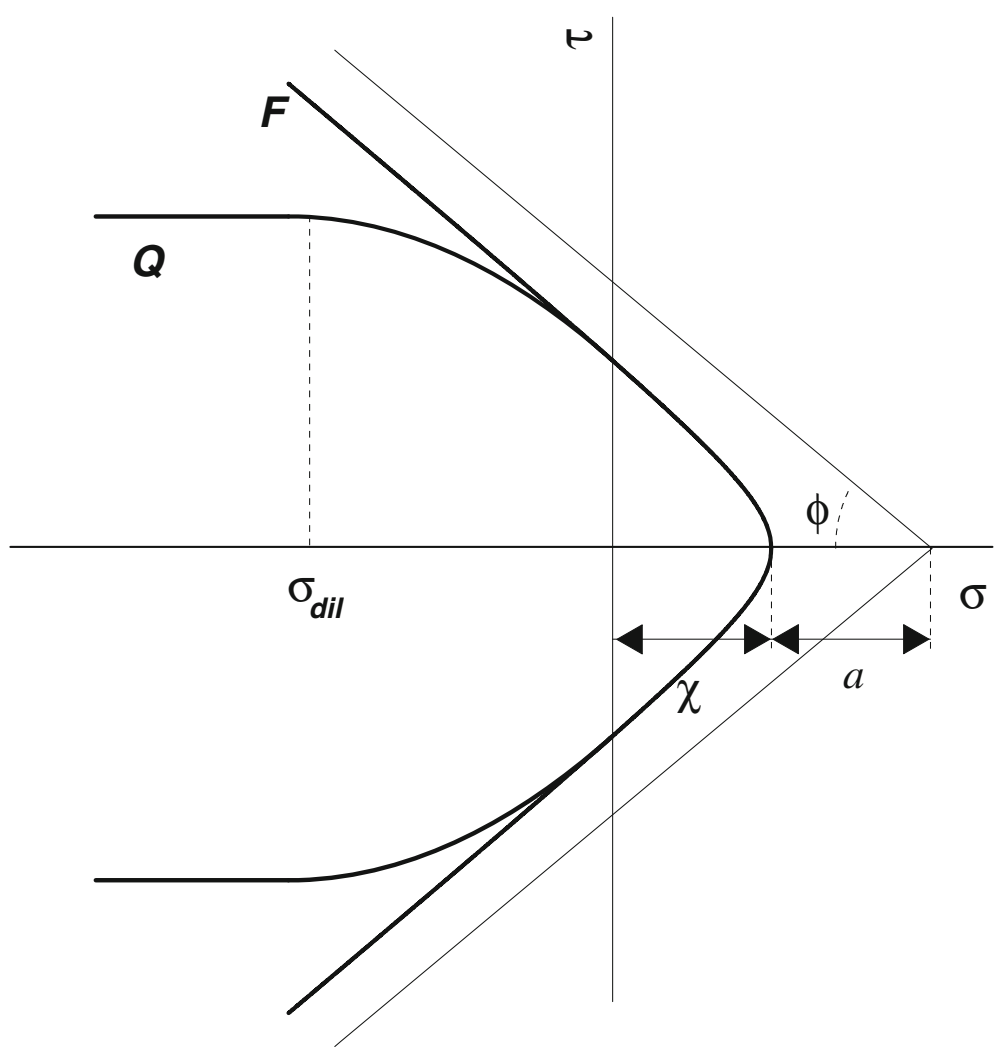

Figure 1. Fracture criterion of the model. 
The opening $\left(\omega_{n}\right)$ and sliding $\left(\omega_{t}\right)$ components of the crack separation can be expressed as the sums of the elastic displacement and the real crack opening as

$$
d \omega_{n}=d \omega_{n}^{e l}+d \omega_{n}^{c r} ; \quad d \omega_{t}=d \omega_{t}^{e l}+d \omega_{t}^{c r},
$$

where the components of the elastic displacement are

$$
d \omega_{n}^{e l}=\frac{d \sigma}{D_{n}} ; \quad d \omega_{t}^{e l}=\frac{d \tau}{D_{t}}
$$

and the real crack opening is defined by the flow rule (using the terminology of plasticity) as

$$
d \omega_{n}^{c r}=d \lambda \frac{\partial Q}{\partial \sigma} ; \quad d \omega_{t}^{c r}=d \lambda \frac{\partial Q}{\partial \tau},
$$

where $d \lambda$ is a multiplier and $Q$ (see figure 1) is equal to $F$ in tension. In compression, $Q$ is defined as

$$
\frac{\partial Q}{\partial \sigma}=2 \tan ^{2} \phi(a+\chi-\sigma) f^{d i l} ; \quad \frac{\partial Q}{\partial \tau}=2 \tau
$$

with

$$
f^{d i l}=\left(1-\frac{|\sigma|}{\sigma_{d i l}}\right) \frac{a+\chi}{a_{0}+\chi_{0}} .
$$

Therefore, the crack opening (or dilatancy) is zero when $|\sigma|$ is equal to the parameter $\sigma_{\text {dil }}$ defined in figure 1 or when $a+\chi=0$. In the uncracked material, $\chi=\chi_{0}$ (i.e., tensile strength) and $a=a_{0}$ (which is a parameter related to the shear strength). The evolutions of $\chi$ and $a$ depend on the energy dissipation $(G)$ during crack propagation, which can be decomposed into the energies dissipated in mode I and mode II. $G$ is expressed in a differential form as

$$
d G=d G^{I}+d G^{I I} .
$$

In this formulation, the differential of the mode I component of $G$ is defined as

$$
d G^{I}=\sigma d \omega_{n}^{c r} \quad \text { if } \quad \sigma \geq 0 ; \quad d G^{I}=0 \quad \text { if } \quad \sigma<0
$$

and that of the mode II component as

$$
\begin{gathered}
d G^{I I}=\tau d \omega_{t}^{c r} \text { if } \quad \sigma \geq 0 \\
d G^{I I}=(|\tau|-|\sigma| \tan \phi)\left|d \omega_{t}^{c r}\right|-|\sigma| d \omega_{n}^{c r} \quad f \quad \sigma<0 .
\end{gathered}
$$

In the above equation, it can be seen that $G^{I I}$ is the difference between the total energy dissipated in shear $\left(\left|\tau d w_{t}^{c r}\right|\right)$, and the sum of the energy dissipated due to friction $\left(\left|\sigma \tan \phi d w_{t}^{c r}\right|\right)$ and that dissipated due to dilatancy $\left(\left|\sigma d w_{n}^{c r}\right|\right)$. Consequently, the treatment of dilatancy is similar to that of friction in the literature (William 1984). $d G^{I I}$ must be greater or equal to 0 , and if $d G^{I I}$ becomes negative in the analysis, the condition of $d G^{I I}=0$ is imposed. This implies that mode II crack propagation is not possible when $d G^{I I}$ is negative.

The general trends of the parameters $a$ and $\chi$ are given by

$$
a=a_{0} \Psi_{a} ; \quad \chi=\chi_{0} \Psi_{\chi},
$$


where, for $n=a$ and $\chi$, respectively:

$$
\Psi_{n}=1-\frac{e^{\alpha_{n}} \xi_{n}}{1+\left(e^{\alpha_{n}}-1\right) \xi_{n}} .
$$

In the following analysis, the values of $\alpha_{\chi}=\alpha_{a}=0$ were chosen. Therefore,

$$
a=a_{0}\left(1-\xi_{a}\right) ; \quad \chi=\chi_{0}\left(1-\xi_{\chi}\right),
$$

where

$$
\begin{aligned}
& \xi_{\chi}=\frac{\int_{0}^{\omega^{c r}} d G^{I}}{G_{F}^{I}}+\frac{\int_{0}^{\omega^{c r}} d G^{I I}}{G_{F}^{I I}} ; \\
& \xi_{a}=\frac{\int_{0}^{\omega^{c r}} d G^{I}+\int_{0}^{\omega^{c r}} d G^{I I}}{G_{F}^{I I}}
\end{aligned}
$$

in which $G_{F}^{I}$ and $G_{F}^{I I}$ are the fracture energies in modes I and II, respectively. It can be seen in Eqs. (15) and (16) that in the case of pure mode I (i.e., $d G^{I I}=0$ ), when the FPZ is fully developed (i.e., $\int_{0}^{\omega^{c r}} d G^{I}=G_{F}^{I}$ ), the cohesive tensile stress vanishes. In pure mode II (i.e., $d G^{I}=0$ ), both $a$ and $\chi$ vanish when the FPZ is fully developed (i.e., $\int_{0}^{\omega^{c r}} d G^{I I}=G_{F}^{I I}$ ).

\subsection{Softening response of the model when crack opens monotonically in mode I}

It is interesting to study the response when the crack opens monotonically in mode I, with an interface element having very high (i.e., theoretically infinite) stiffness. Under these conditions it is possible to obtain the softening function explicitly, taking into account that in mode I the model is associated $(Q=F)$. For this $\sigma$ must be obtained by integrating the equation:

$$
\begin{aligned}
d \sigma & =D_{n} d \omega_{n}^{e l}=D_{n}\left(d \omega_{n}-d \omega_{n}^{c r}\right)=D_{n}\left(d \omega_{n}-d \lambda \frac{\partial Q}{\partial \sigma}\right) \\
& =D_{n} d \omega_{n}-2 D_{n} d \lambda \tan ^{2} \phi(a+\chi-\sigma)
\end{aligned}
$$

On the other hand, $d \lambda$ is given by (Carol et al 1994)

$$
d \lambda=\frac{\frac{d F}{d \sigma} D_{n} d \omega_{n}}{H+\frac{d F}{d \sigma} D_{n} \frac{d F}{d \sigma}}=\frac{2 \tan ^{2} \phi(a+\chi-\sigma) D_{n} d \omega_{n}}{H+4 \tan ^{4} \phi(a+\chi-\sigma)^{2} D_{n}},
$$

where $H$ is the hardening modulus (or rather, in this case, the softening modulus). Substituting Eq. (18) in Eq. (17), we obtain

$$
\begin{aligned}
d \sigma & =D_{n} d \omega_{n}\left(1-\frac{4 D_{n} \tan ^{4} \phi(a+\chi-\sigma)^{2}}{H+4 \tan ^{4} \phi(a+\chi-\sigma)^{2} D_{n}}\right) \\
& =\frac{H D_{n} d \omega_{n}}{H+4 \tan ^{4} \phi(a+\chi-\sigma)^{2} D_{n}} .
\end{aligned}
$$


The definition of $H$ is

$$
H=-\left.\frac{\partial F}{\partial \lambda}\right|_{\sigma=\mathrm{const}}=\left.\left(\frac{\partial F}{\partial p_{i}} \frac{\partial p_{i}}{\partial G} \frac{\partial G}{\partial \omega_{j}^{c r}} \frac{\partial \omega_{j}^{c r}}{\partial \lambda}\right)\right|_{\sigma=\mathrm{const}},
$$

where $p=(\tan \phi, \chi, a)$. Since $\frac{\partial \tan \phi}{\partial \omega_{j}^{c r}}=0$, it can be rewritten as

$$
\begin{gathered}
\left.\frac{\partial F}{\partial \lambda}\right|_{\sigma=\text { const }}=\left.\left(\frac{\partial F}{\partial \chi} \frac{\partial \chi}{\partial G}+\frac{\partial F}{\partial a} \frac{\partial a}{\partial G}\right)\right|_{\sigma=\text { const }} \\
\left.\left(\frac{\partial G}{\partial \omega_{n}^{c r}} \frac{\partial \omega_{n}^{c r}}{\partial \lambda}+\frac{\partial G}{\partial \omega_{t}^{c r}} \frac{\partial \omega_{t}^{c r}}{\partial \lambda}\right)\right|_{\sigma=\text { const }} .
\end{gathered}
$$

From Eq. (6) and considering that the model is associated in tension, we obtain

$$
\left.\frac{\partial \omega_{n}^{c r}}{\partial \lambda}\right|_{\sigma=\text { const }}=\left.\frac{\partial Q}{\partial \sigma}\right|_{\sigma=\text { const }}=2 \tan ^{2} \phi(a+\chi-\sigma) ;\left.\quad \frac{\partial \omega_{t}^{c r}}{\partial \lambda}\right|_{\sigma=c o n s t}=2 \tau=0 .
$$

The other derivatives that appear in Eq. (21) are

$$
\begin{gathered}
\frac{\partial a}{\partial G^{I}}=-\frac{a_{0}}{G_{F}^{I I}} ; \frac{\partial \chi}{\partial G^{I}}=-\frac{\chi_{0}}{G_{F}^{I}} \\
\frac{\partial F}{\partial \chi}=-2 a \tan ^{2} \phi ; \frac{\partial F}{\partial a}=2 \tan ^{2} \phi(\sigma-\chi) \\
\frac{\partial G^{I}}{\partial \omega_{n}^{c r}}=\sigma ; \frac{\partial G^{I}}{\partial \omega_{t}^{c r}}=\tau=0 .
\end{gathered}
$$

Substituting the values of the derivatives in Eq. (21), we get

$$
H=4 \sigma \tan ^{4} \phi(a+\chi-\sigma)\left((\sigma-\chi) \frac{a_{0}}{G_{F}^{I I}}-a \frac{D_{n}}{G_{F}^{I}}\right),
$$

and when we consider that in mode I, $\sigma=\chi$, Eq. (24) becomes

$$
H=-4 \sigma \tan ^{4} \phi a^{2} \frac{\chi_{0}}{G_{F}^{I}}
$$

Substituting Eq. (25) in Eq. (19), we get

$$
d \sigma=\frac{1}{1-\frac{G_{F}^{I} D_{n}}{\chi_{0}^{\sigma}}} D_{n} d \omega_{n}
$$

which can be integrated through the separation of variables. If we consider that value of $\omega_{n}$ is given by

$$
\omega_{n}=\omega_{n}^{e l}+\omega_{n}^{c r}=\frac{\sigma}{D_{n}}+\omega_{n}^{c r}
$$


we have $\omega_{n}=\omega_{n}^{c r}$ for $D_{n} \rightarrow \infty$ since $D_{n}$ has to be theoretically infinite though in practice it is chosen to be a large finite value. Then, substituting this in the solution of Eq. (26), the softening function is obtained as

$$
\sigma=\chi_{0} e^{-\frac{\chi_{0}}{G_{F}^{I}} \omega_{n}}
$$

which coincides with an exponential softening model (García-Álvarez et al 1994).

\subsection{Selection of parameter $a_{0}$}

For the selection of $a_{0}$, a minimum value can be established by analysing its relation with the parameters $\tan \phi$ and $\chi_{0}$. Considering the case of a crack passing through the interface element, families of possible Mohr circles corresponding to a Gauss point of the element can be studied at the instant in which the crack tip is at this point and the crack starts opening in mode I. Since $\sigma=\chi_{0}$ and $\tau=0$ in mode I, only those that satisfy these conditions must be considered among all the possible Mohr circles.

The first possible family of Mohr circles that fulfill all the above-mentioned conditions is composed of circles that are tangential to the y-axis on its left (see figure 2). This corresponds to the

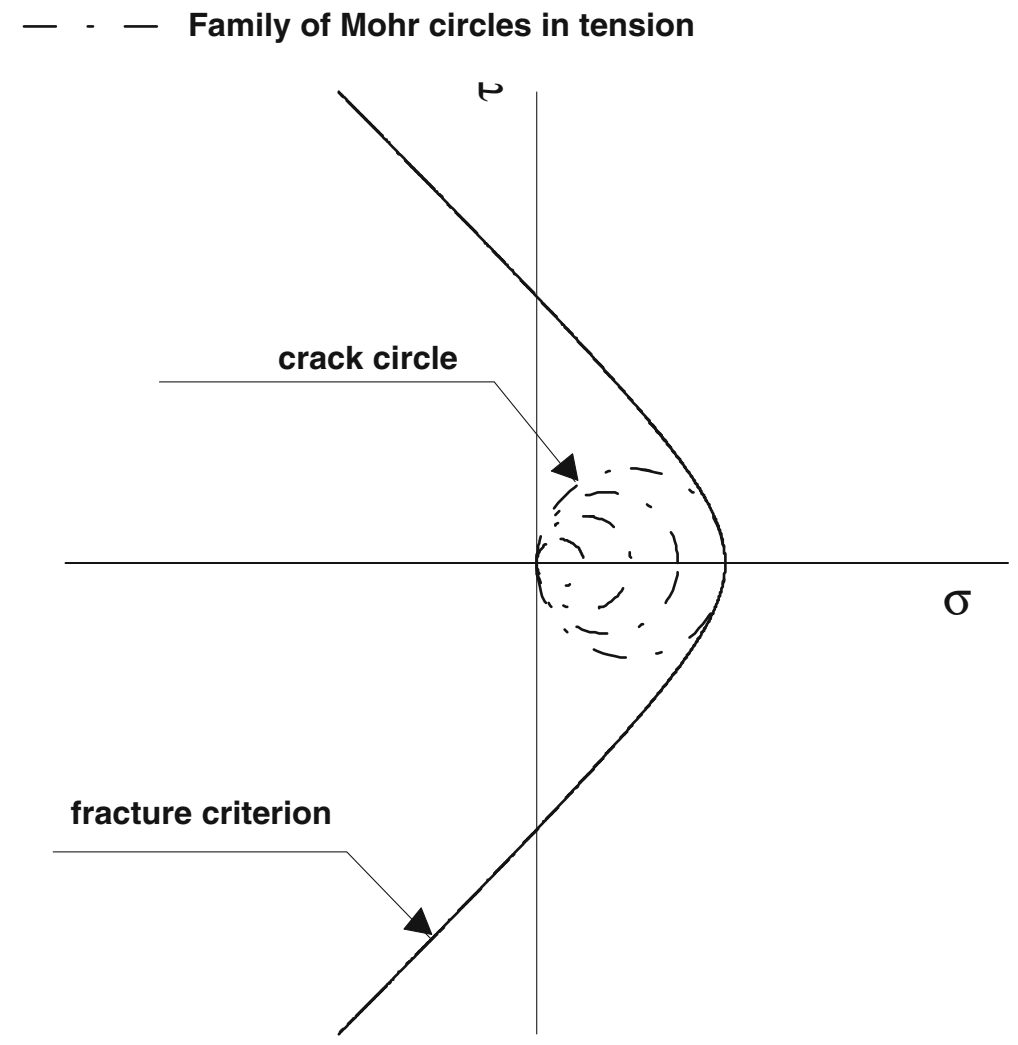

Figure 2. First family of Mohr circles considered. 
case of the normal stresses at the Gauss point being tensile in all the directions. At the crack-tip, the Mohr circle is tangential to the fracture criterion curve at its vertex (figure 2). This circle fulfils the conditions of $\sigma=\chi_{0}$ and $\tau=0$ when

$$
a_{0} \geq \frac{\chi_{0}}{2 \tan ^{2} \phi}
$$

This is obtained by equating the radius of the Mohr circle considered $\left(\chi_{0}\right)$ with the radius of curvature of the hyperbola whose parameters are $a_{0}, \chi_{0}$ and $\tan \phi$.

Another possible family of Mohr circles is that with their centers at the origin (figure 3). In this case, it is assumed that compression can exist in some direction at the Gauss point on the crack tip. Therefore, with the same tangency condition used above, the circle fulfils the conditions imposed on $\sigma$ and $\tau$ if

$$
a_{0} \geq \frac{\chi_{0}}{\tan ^{2} \phi}
$$

When $a_{0}=\chi_{0} / \tan ^{2} \phi$ in pure compression (figure 3), the maximum stress $\left(\sigma_{m}\right)$ is reached for $\sigma_{m}=-14.167 \chi_{0}$ if $\tan \phi=0.7$, and $\sigma_{m}=-10 \chi_{0}$ if $\tan \phi=0.75$. Consequently, if Eq. (30) is satisfied strictly, the resulting relation between the compressive and tensile strengths is within the usual range for concrete. Therefore, a value of $a_{0}$ nearly equal to $\chi_{0} / \tan ^{2} \phi$ is proposed.

\section{- - Family of Mohr circles considered}

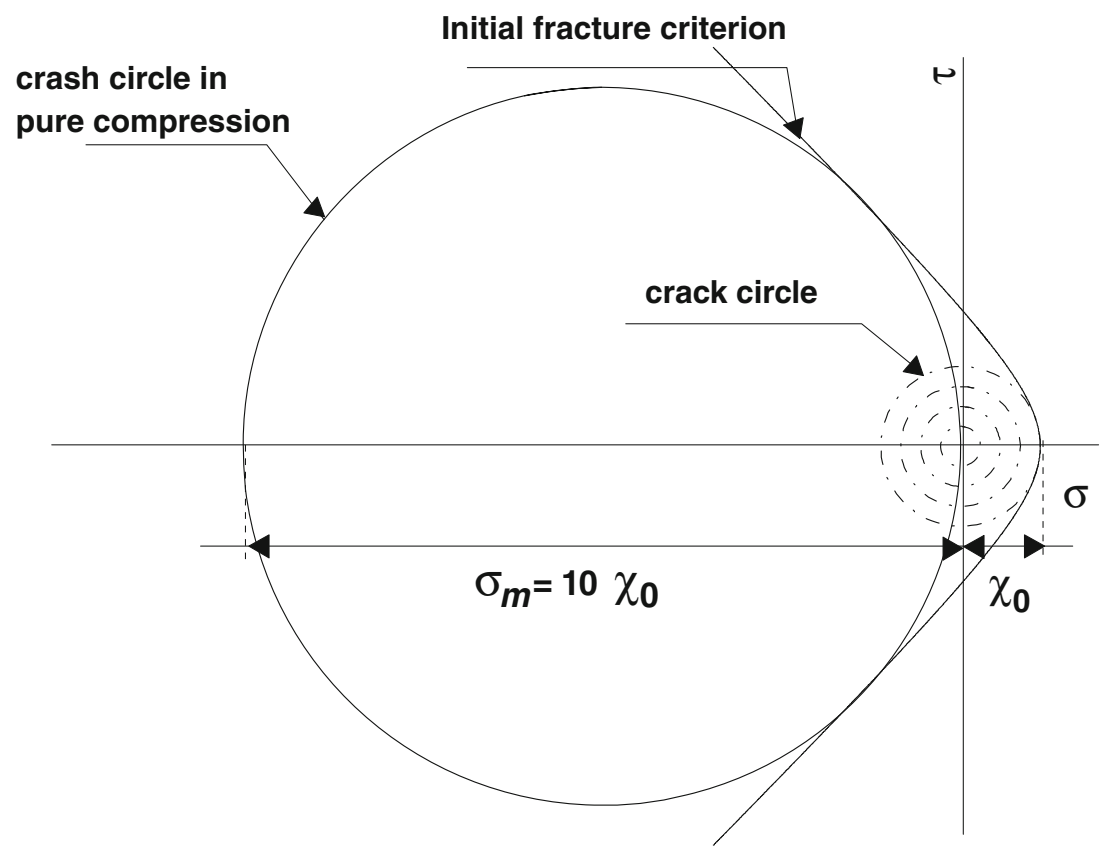

Figure 3. Second family of Mohr circles considered. 


\section{Verification of the model using tests of notched concrete beams of different sizes}

\subsection{Background}

A simple geometry for studying non-planar fracture in concrete is the eccentrically notched beam under 3PB. This type of specimen has been used previously by other researchers to study mixed-mode fracture (Jenq \& Shah 1988). In the present work, the model is applied to tests of normal strength concrete under this configuration. In addition, comparisons are made with the results from the analysis of centre-notched beams of normal strength concrete and a more brittle high strength concrete.

\subsection{Experimental details}

The experimental study was performed on a high-strength concrete (HSC) with $50 \mathrm{MPa}$ characteristic cylinder compressive strength and a normal-strength concrete (NSC) with $20 \mathrm{MPa}$ characteristic strength. The NSC had the proportions of cement:sand:gravel:water as 1:2.5:3.75:0.65 with CEM I 42.5R cement, limestone gravel $(5-12 \mathrm{~mm})$ and siliceous sand $(0-5 \mathrm{~mm})$. The HSC had the proportions of cement:sand:gravel:microsilica:water as 1:1.25:1.8:0.2:0.3 with CEM I $52.5 \mathrm{R}$ cement, densified silica fume, crushed basalt gravel $(5-12 \mathrm{~mm})$, siliceous sand $(0-5 \mathrm{~mm})$ and a melamine-based superplasticizer.

Three batches of NSC (denoted A, B and C) and four of HSC were fabricated, and in each of them, nine beams were cast with the geometry shown in figure 4 , three in each size, with $d=$ 80,160 and $320 \mathrm{~mm}$, and thickness $(b)$ of $50 \mathrm{~mm}$. Notches of length $l=0.25 d$ for NSC and $l=$ $0.275 d$ for HSC were cut with a diamond disc saw, with the eccentricities $(e)$ of $0.625 d(0.25 s)$ for series A and $0.3125 d(0.125 s)$ for series $\mathrm{B}$, respectively, and at mid-span $(e=0)$ for series C. In the HSC, the notches were cut only at mid-span $(e=0)$. The tests of the NSC beams were performed at the age of 730 days, and those of the HSC beams at the age of 31 days. All the specimens were maintained in a fog room until testing.

All the tests were conducted in a $1 \mathrm{MN}$ INSTRON servohydraulic machine under closedloop control and constant crack mouth displacement (CMD) rates that led to peak loads at about 3 minutes. The load-CMD curves obtained are shown later with the fits of the cohesive crack model.

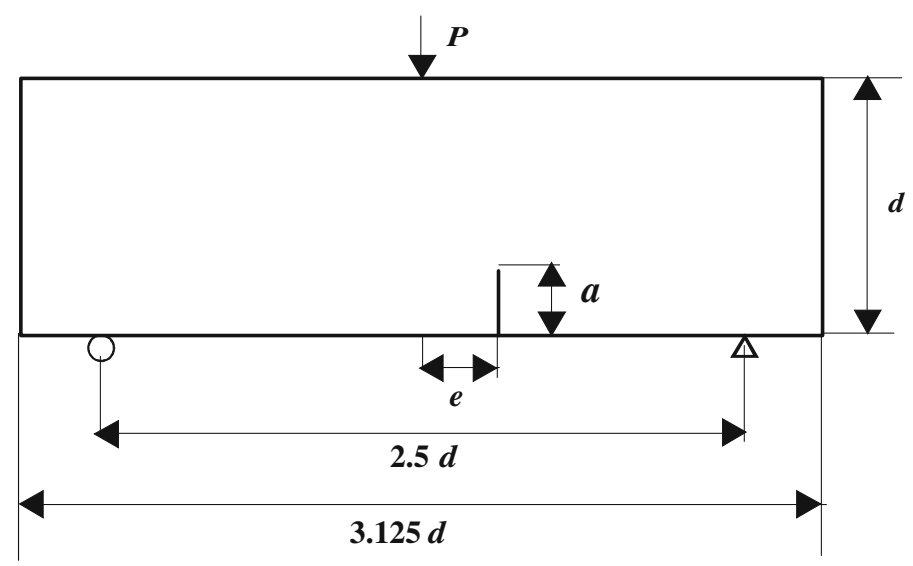

Figure 4. Three-point bending specimen. 


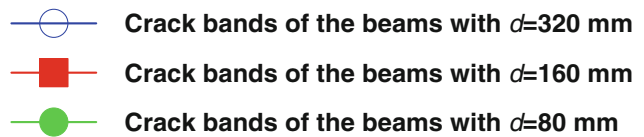

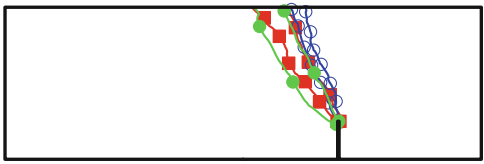

(a)

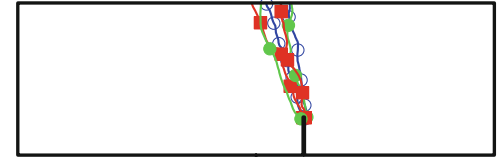

(b)

Figure 5. Crack bands for (a) $e=0.25 s$ and (b) $e=0.125 s$.

The crack paths observed on the surfaces of the specimens were recorded and crack bands for each eccentricity were obtained from them. Figures $5 \mathrm{a}$ and $\mathrm{b}$ show the bands for $e \neq 0$, from which it can be concluded that the crack path does not depend significantly on the specimen size (i.e., they are geometrically similar). Note that the bands for different sizes have been normalized with respect to the beam depth for the comparison. This agrees with the results of other nonplanar fracture tests in the literature (Bocca et al 1991).

\subsection{Numerical details and implementation}

In order to apply the model formulated in the previous section to the 3PB specimen, the uncracked part is represented with triangular and quadrilateral finite elements, and the crack path by interface elements. In non-planar cases, the average crack paths obtained from the experimental bands (figure 5) were used while in mode I the crack path is taken to be straight (i.e., along the axis of symmetry of beam). The computations were made with quadratic analysis, using the Gauss $3 \times 3$ integration rule in quadrilateral elements and the 7-point Gauss rule in triangular elements, and the 3-point Newton-Cotes rule in the interfaces (figure 6). The choice of the integration rule for the interface element is important since the Gauss rule lead to results with spurious jumps in the strain and stress fields (Garcia-Alvarez et al 1994; Gens et al 1988; Schellekens 1990). Therefore, the 3-point Newton-Cotes rule, as proposed in Gens et al (1988), was chosen.
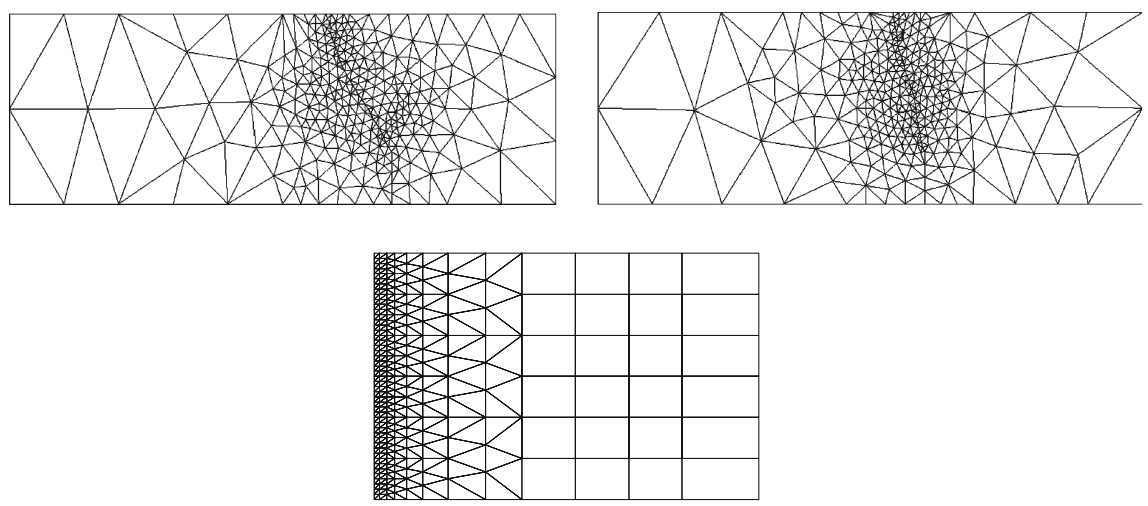

Figure 6. Meshes used for $e=0.25 s$, for $e=0.125 s$, and for $e=0$ (mesh for one half of the beam). 
In order to obtain stable solutions beyond the peak load, a displacement control method (Crisfield 1994) is used for increasing the CMD monotonically in the analysis, as described in a previous work (García-Álvarez 1997). The calculations take into account the weight of the concrete. In the case of mode I, the simplification derived in section 2.2 was used.

\subsection{Numerical results}

In the analyses of NSC, values of Young's modulus $(E)=33.8 \mathrm{GPa}$ (obtained from the initial slope of the experimental curves) and Poisson ratio $(v)=0.2$ were used. The elastic stiffness coefficients of the interfaces $D_{n}$ and $D_{t}$ were taken as $10^{8} \mathrm{~N} / \mathrm{m}$. The parameter $a_{0}$ was chosen to be $9 \mathrm{MPa}$ since this gives a ratio of 10 between the compressive and tensile strengths. In order to consider a reasonable relation between $G_{F}^{I I}$ and $G_{F}^{I}$, a parametric study was conducted (GarcíaÁlvarez 1997) with the specimen with $e=0.25 \mathrm{~s}$. The results of this study indicated a $G_{F}^{I I} / G_{F}^{I}$ ratio of 1 could be used. The other two parameters of the model $\left(G_{F}^{I}, \chi_{0}\right)$ were obtained by backfitting the experimental load-CMD curves. The data for each eccentricity (i.e., the results for all the specimen sizes) were analysed jointly in order to reduce the uncertainty of the parameter set.

The experimental data for each eccentricity and their optimum fits are shown in figures $7 \mathrm{a}, \mathrm{b}$ and $\mathrm{c}$. The parameter set that gives satisfactory simulations of the load-CMD responses in all the cases is $G_{F}^{I}=80 \mathrm{~J} / \mathrm{m}^{2}$ and $\chi_{0}=3.5 \mathrm{MPa}$.
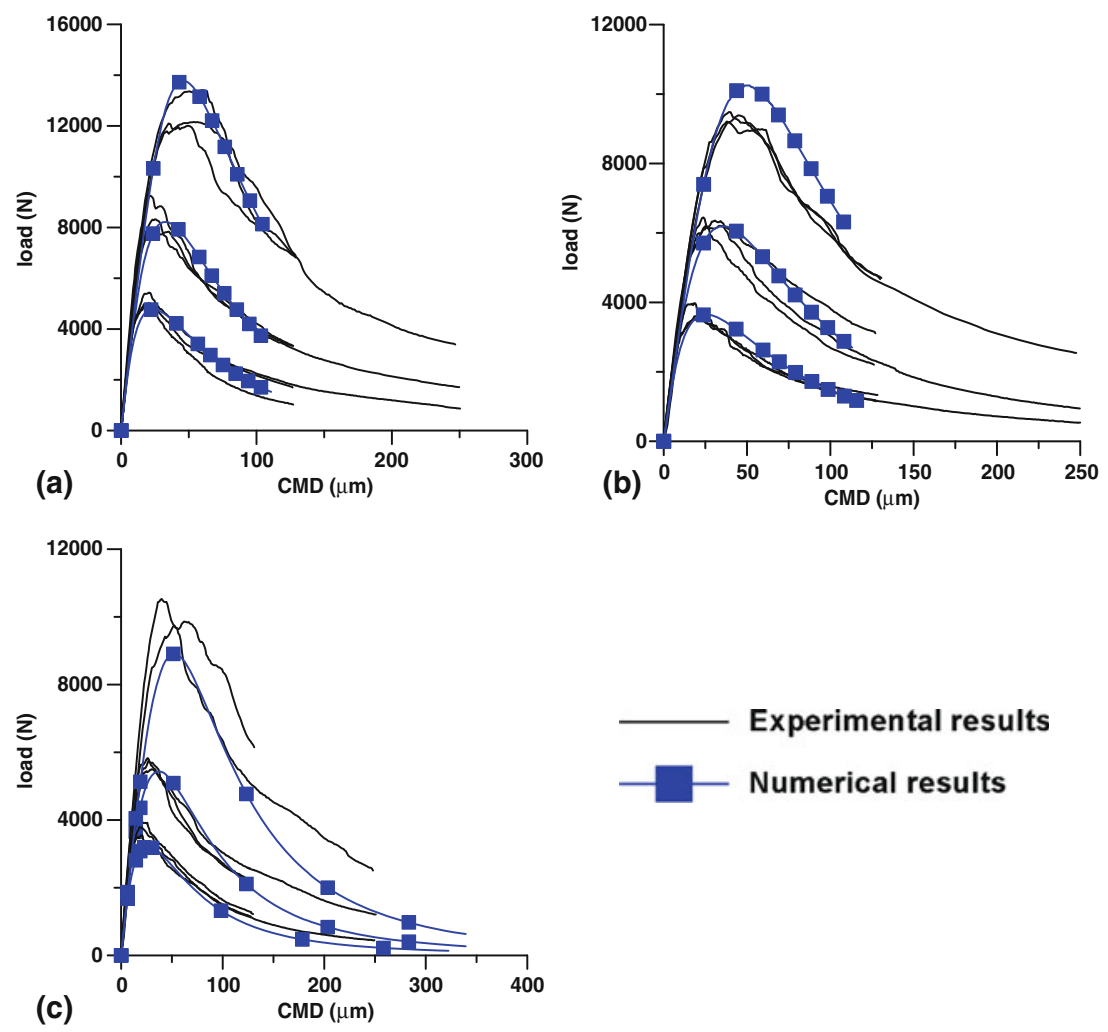

Figure 7. Experimental data with the analytical fits for (a) $e=0.25 s,(\mathbf{b}) e=0.125 \mathrm{~s}$ and (c) $e=0$. 

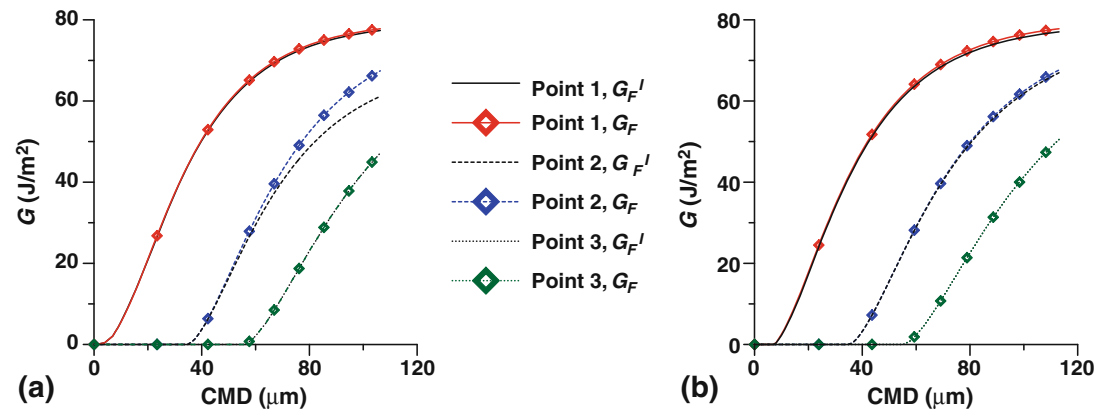

Figure 8. Evolution of the total and mode I energy dissipation.

The mode II fracture component is not significant in the cases analysed here, as confirmed from the comparisons of the evolution of the total energy dissipation, $G$, with that of the mode I energy dissipation, $G^{I}$. In figures $8 \mathrm{a}$ and $\mathrm{b}$, these comparisons are given for $e=0.25 \mathrm{~s}$ and $e=$ $0.125 \mathrm{~s}$, respectively, at three points along the crack path: (1) at the notch tip; (2) at one-fourth of the crack length from the notch tip; and (3) at the middle of the crack path. In all the cases,
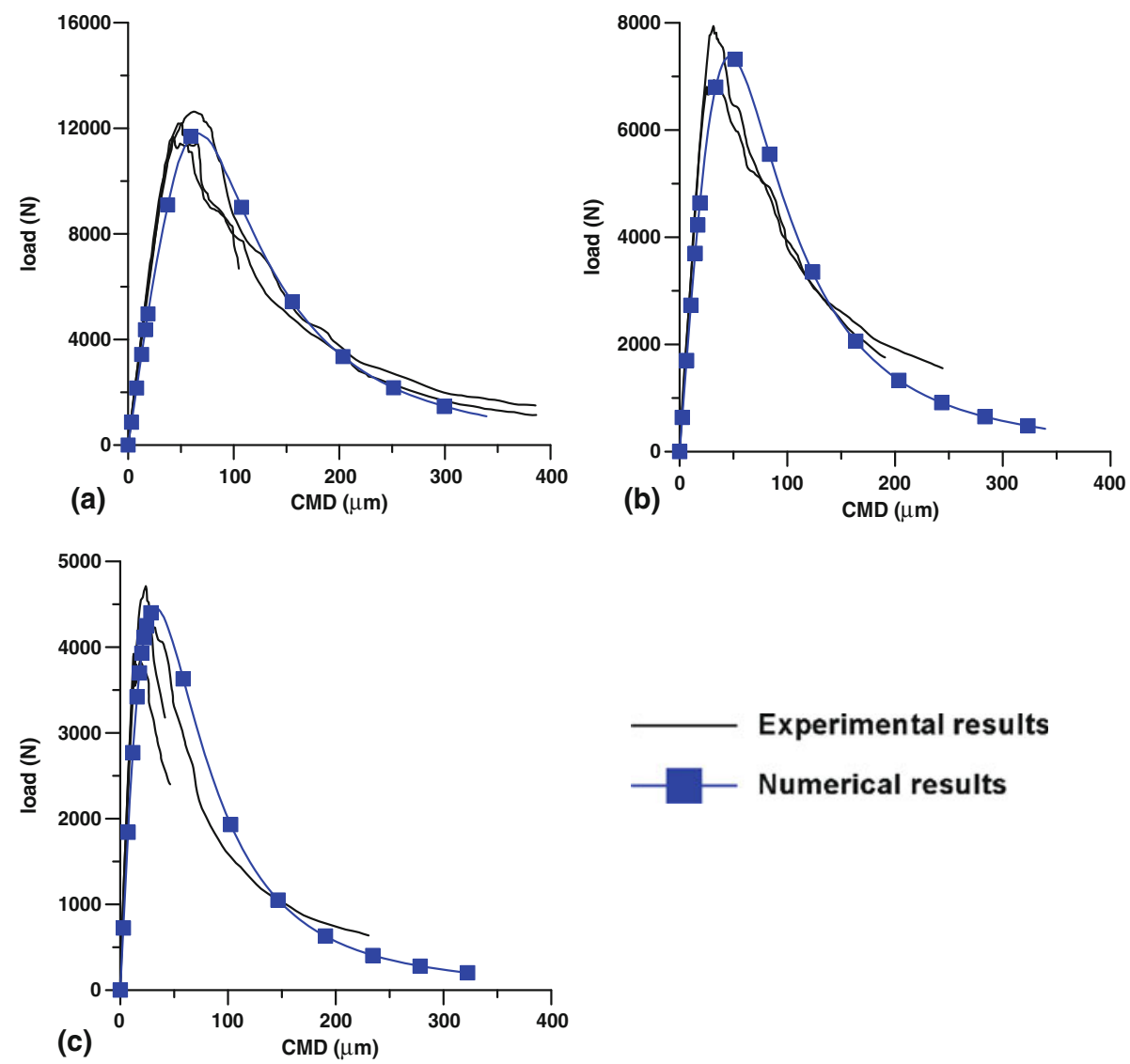

Experimental results

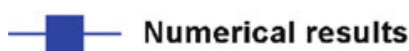

Figure 9. Experimental data with the analytical fits for (a) $d=320 \mathrm{~mm},(\mathbf{b}) d=160 \mathrm{~mm}$ and (c) $d=$ $80 \mathrm{~mm}$. 
Table 1. Values of $l_{c h}$.

\begin{tabular}{lcccc}
\hline & $\mathrm{G}_{F}\left(\mathrm{~J} / \mathrm{m}^{2}\right)$ & $\chi_{0}(\mathrm{MPa})$ & $E(\mathrm{GPa})$ & $l_{c h}(\mathrm{~m})$ \\
\hline NSC & 80 & 3.5 & 33.8 & 0.22 \\
$\mathrm{HSC}$ & 120 & 6.0 & 36.8 & 0.12 \\
\hline
\end{tabular}

the evolutions of $G$ and $G^{I}$ practically coincide implying that $G^{I I}$ is negligible. This suggests that the non-planar crack propagation in the specimens studied here is basically a case of mode I failure and not mixed-mode.

In the analysis of the HSC specimens, the values of $E=36.8 \mathrm{GPa}$ (obtained from the experimental curves) and Poisson ratio $(v)=0.2$ were used. The elastic stiffness coefficients of the interfaces $D_{n}$ and $D_{t}$ were again taken as $10^{8} \mathrm{~N} / \mathrm{m}$. The experimental data for each size and their optimum fits are shown in figures $9 \mathrm{a}, \mathrm{b}$ and $\mathrm{c}$. The parameter set that gives the most satisfactory simulations of the load-CMD responses in all the cases is $G_{F}^{I}=120 \mathrm{~J} / \mathrm{m}^{2}$ and $\chi_{0}=6 \mathrm{MPa}$.

One interesting result that can be obtained from the parameters is the comparison of the brittleness of HSC with that of NSC through the Hillerborg characteristic length (Gettu \& Shah 1994), which is a measure of the pseudo-ductility of the material during failure:

$$
l_{c h}=\frac{E G_{F}}{\chi_{0}^{2}} .
$$

The values of $l_{c h}$ obtained from the model parameters are shown in table 1, for NSC and HSC. The lower $l_{c h}$-value for HSC reflects the higher brittleness of this material when compared with NSC, which is in accordance with accepted trends in the literature (Gettu \& Shah 1994).

\section{Application of the model to Hassanzadeh's test}

\subsection{Test details}

In order to verify the trends given by the present model in the case of fracture dominated by the shear mode, the tests performed by Hassanzadeh (1990, 1992); di Prisco et al (2000) have been analysed since this series of tests is often considered as an international benchmark for numerical analysis. In these tests, the cracking was initiated in tension and further propagation was driven by shear stresses. However, as the crack faces separate and slide with respect to one another, the fracture propagation can be considered to occur in mixed mode.

The experimental study of Hassanzadeh was performed on prisms of $60 \mathrm{~mm}$ height with a square section of $70 \times 70 \mathrm{~mm}$. At mid-height a notch of $15 \mathrm{~mm}$ length was cut around the perimeter, leaving a ligament of $40 \times 40 \mathrm{~mm}$ through which the crack propagates (figure 10).

The specimens were tested under displacement control with different load histories, all of which begin with an initial step where uniaxial tension is applied until the tensile strength is reached. Later, the specimen is subjected (Hassanzadah 1990, 1992; Olofsson et al 1995) to the displacement vector $\left(\omega_{n}^{c r}, \omega_{t}^{c r}\right)$ given by

$$
\omega_{n}^{c r}=\tan \gamma \cdot \omega_{t}^{c r},
$$

where $\gamma$ has values of $30^{\circ}, 45^{\circ}, 60^{\circ}$ and $90^{\circ}$. The directions of the shear displacement component, $\omega_{t}^{c r}$, and the normal component, $\omega_{n}^{c r}$, are parallel and perpendicular to the ligament or notch plane, respectively. 

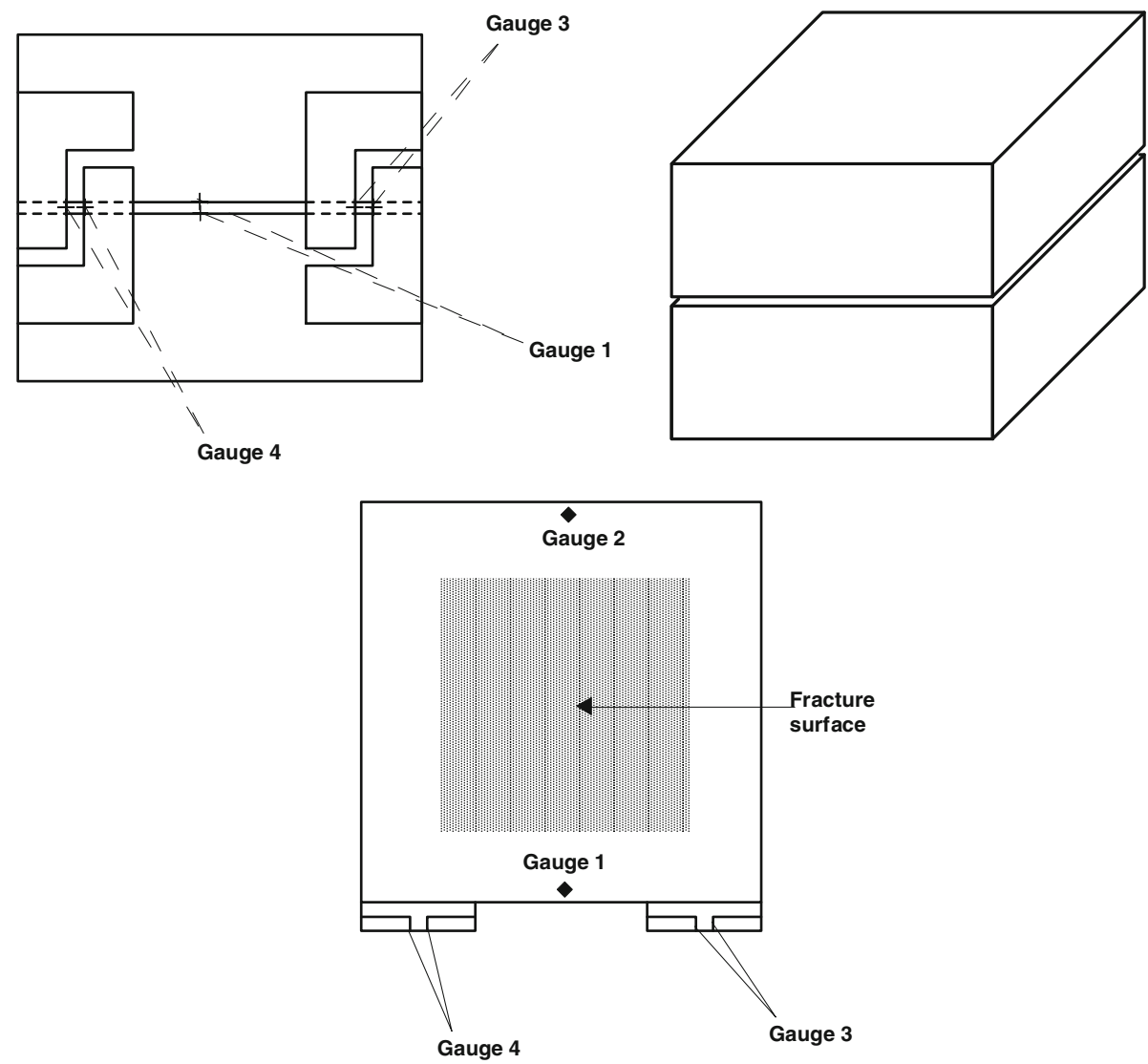

Figure 10. Hassanzadeh's specimen and the locations of the gauges used (Hassanzadeh 1990).
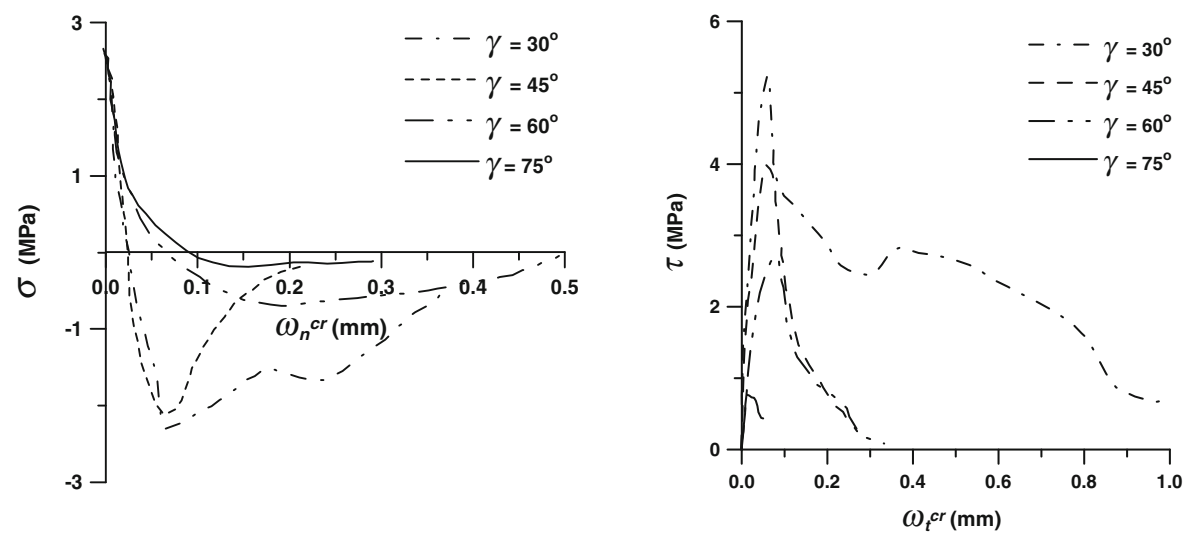

Figure 11. Results obtained from Hassanzadeh's tests (Hassanzadeh 1990). 
Notch

- - - - Interface element

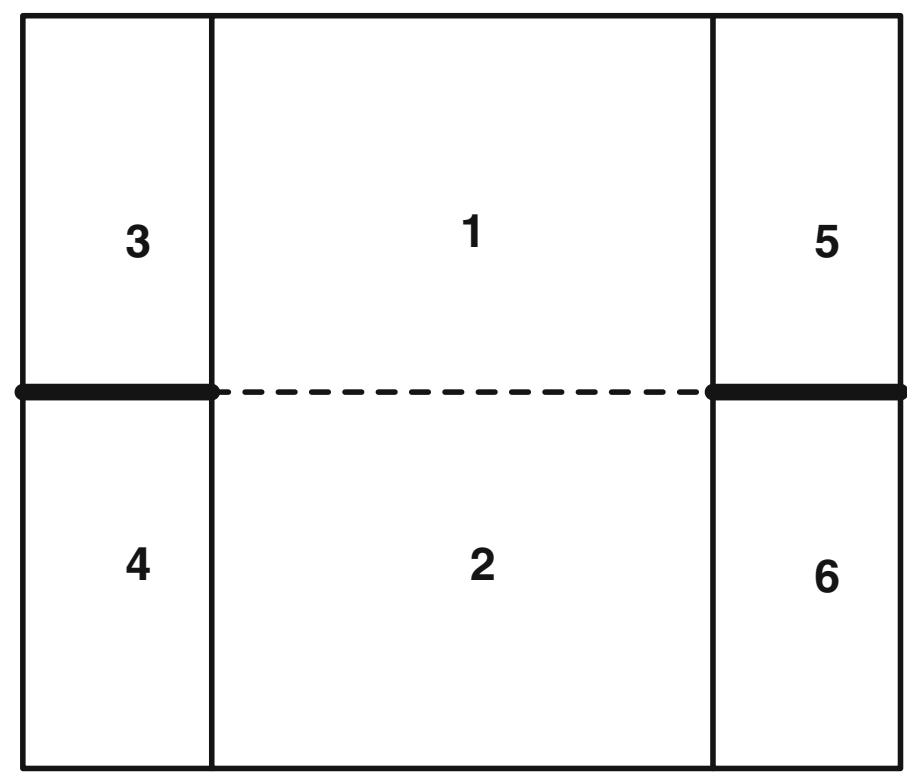

Figure 12. Meshes used for modelling Hassanzadeh's tests.

From the test results obtained by Hassanzadeh, as shown in figure 11, three constitutive aspects of the specimen response can be deduced:

(i) With a decrease in $\gamma$, the pre-peak slope of the $\sigma-\omega_{n}^{c r}$ curve increases (i.e., $\sigma$ decreases at a higher rate for lower values of $\gamma$ ) as the crack propagates.

(ii) With a decrease in $\gamma$, higher compressive stresses are generated due to dilatancy.

(iii) With a decrease in $\gamma$, the maximum shear stress increases.
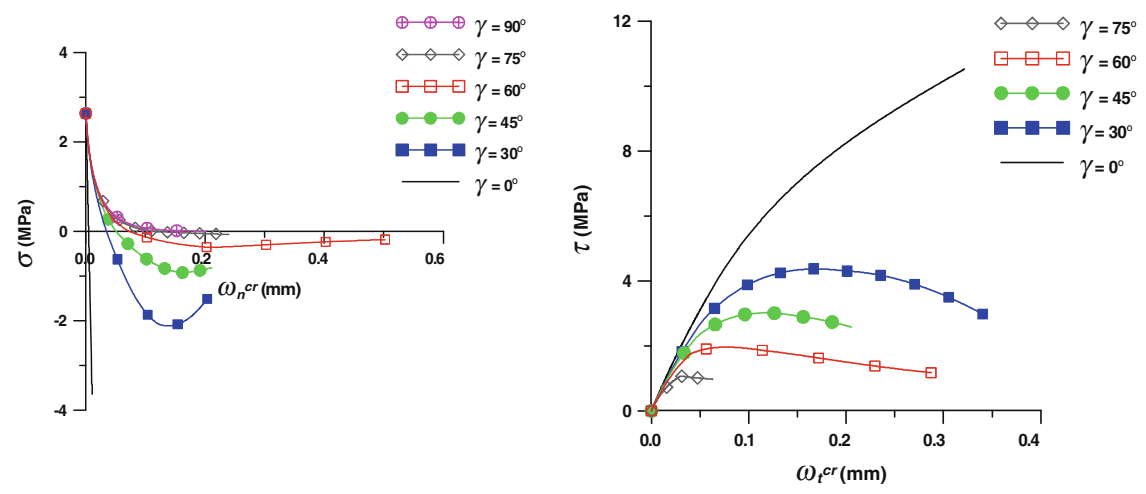

Figure 13. Results obtained from the numerical analysis. 

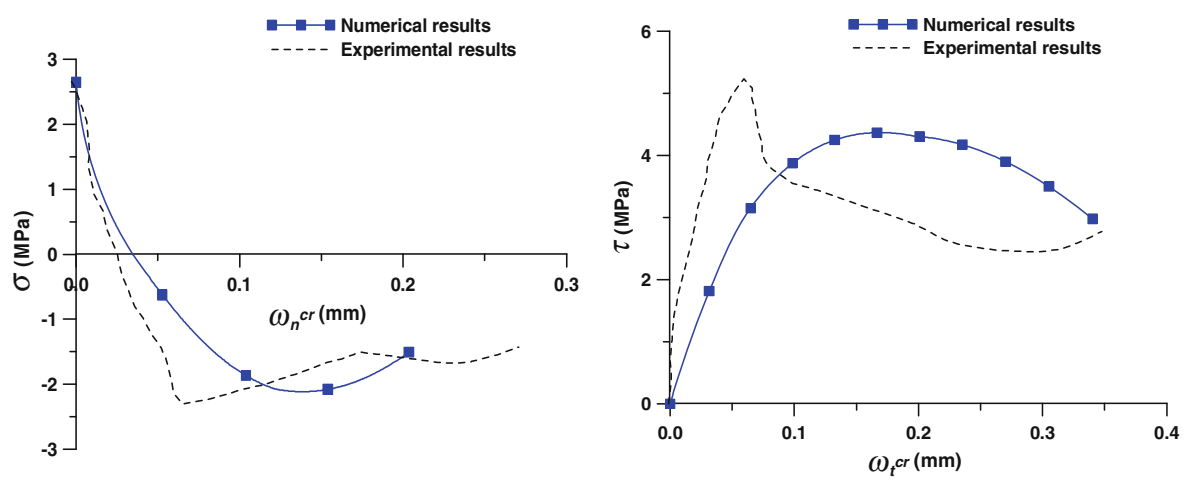

Figure 14. Results for $\gamma=30^{\circ}$.

\subsection{Analysis of the specimen response}

The analysis was performed in plane strain (two-dimensions) with a coarse mesh consisting of six finite elements and an interface element, as seen in figure 12. The computations were made with quadratic analysis, using the Gauss $3 \times 3$ integration rule in quadrilateral elements and the 3-point Newton-Cotes rule in the interfaces. Displacement and stresses tolerances were set as $10^{-5}$.

The parameters of the continuum elements are $E=30 \mathrm{GPa}$ and $v=0.2$ and the parameters of the interface elements are $D_{n}=D_{t}=10^{5} \mathrm{~N} / \mathrm{m}, \tan \phi=0.75, \chi_{0}=2.8 \mathrm{MPa}, a_{0}=16 \mathrm{MPa}$, $G_{F}^{I}=100 \mathrm{~J} / \mathrm{m}^{2}, G_{F}^{I I}=1000 \mathrm{~J} / \mathrm{m}^{2}, \sigma_{d i l}=100 \mathrm{MPa}$ and $\alpha_{\chi}=\alpha_{c}=0$. The parameters $E, \chi_{0}$ and $G_{F}^{I}$ have been estimated from the data given by Hassanzadeh (1990) and those used by Olofsson et al (1995) for the same tests. The displacements and stresses obtained from the modelling take into account the gage locations in the tests (figure 10). Consequently, the shear displacements shown in figure 13 correspond to the average of the displacement of left side of element 3 and

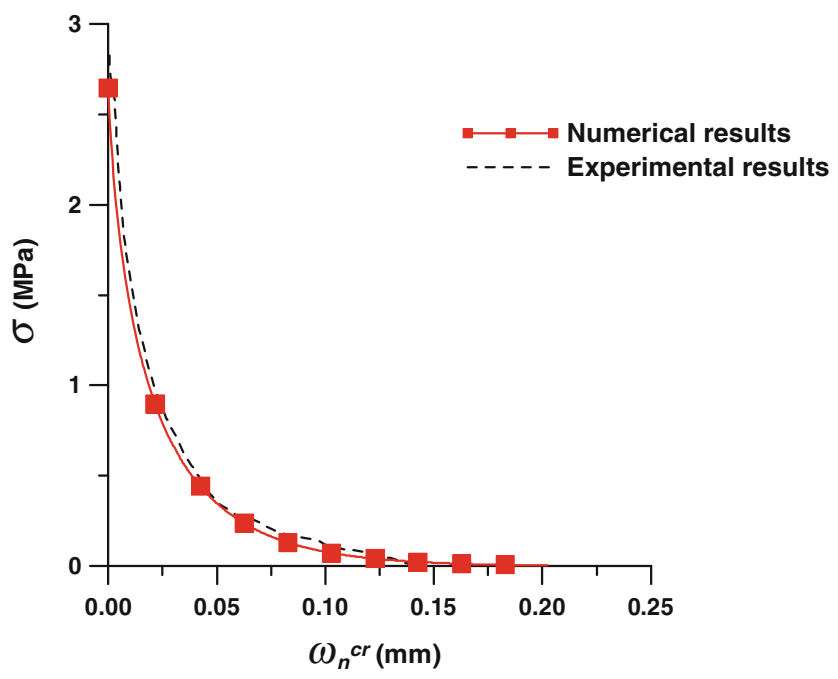

Figure 15. Results for $\gamma=90^{\circ}$. 
right side of element 5, and the crack opening is that at the middle of the interface element. The normal and shear stresses ( $\sigma$ and $\tau$, respectively) have been obtained from the values of the reactions obtained in the analysis, at the upper side of elements 1, 3 and 5. The results in figure 13 show the numerical responses for the different $\gamma$-values used by Hassanzadeh, along with the case of $\gamma=0$ (i.e., crack propagation under pure shear).

It can be observed that the model reproduces the trends of the constitutive behaviour correctly; i.e., for lower values of $\gamma$, the pre-peak slope of the $\sigma-\omega_{n}^{c r}$ curve, the compressive stresses and the maximum shear stress are all higher.

In figures 14 and 15, the test and analytical results are compared for $\gamma$-values of $30^{\circ}$ and $90^{\circ}$, where it can be seen that the model performs satisfactorily, even though the tortuosity or roughness of the crack was not taken into account. The fact that the analytical results did not match the experimental values can be attributed to the inability to actual notch dimensions, crack paths and boundary conditions in the modelling, as such data were not reported.

In figure 16, the analytically-obtained stress paths are shown for different values of $\gamma$. It is interesting to observe the evolution of the hyperbola for each $\gamma$ as the crack propagates, i.e., as
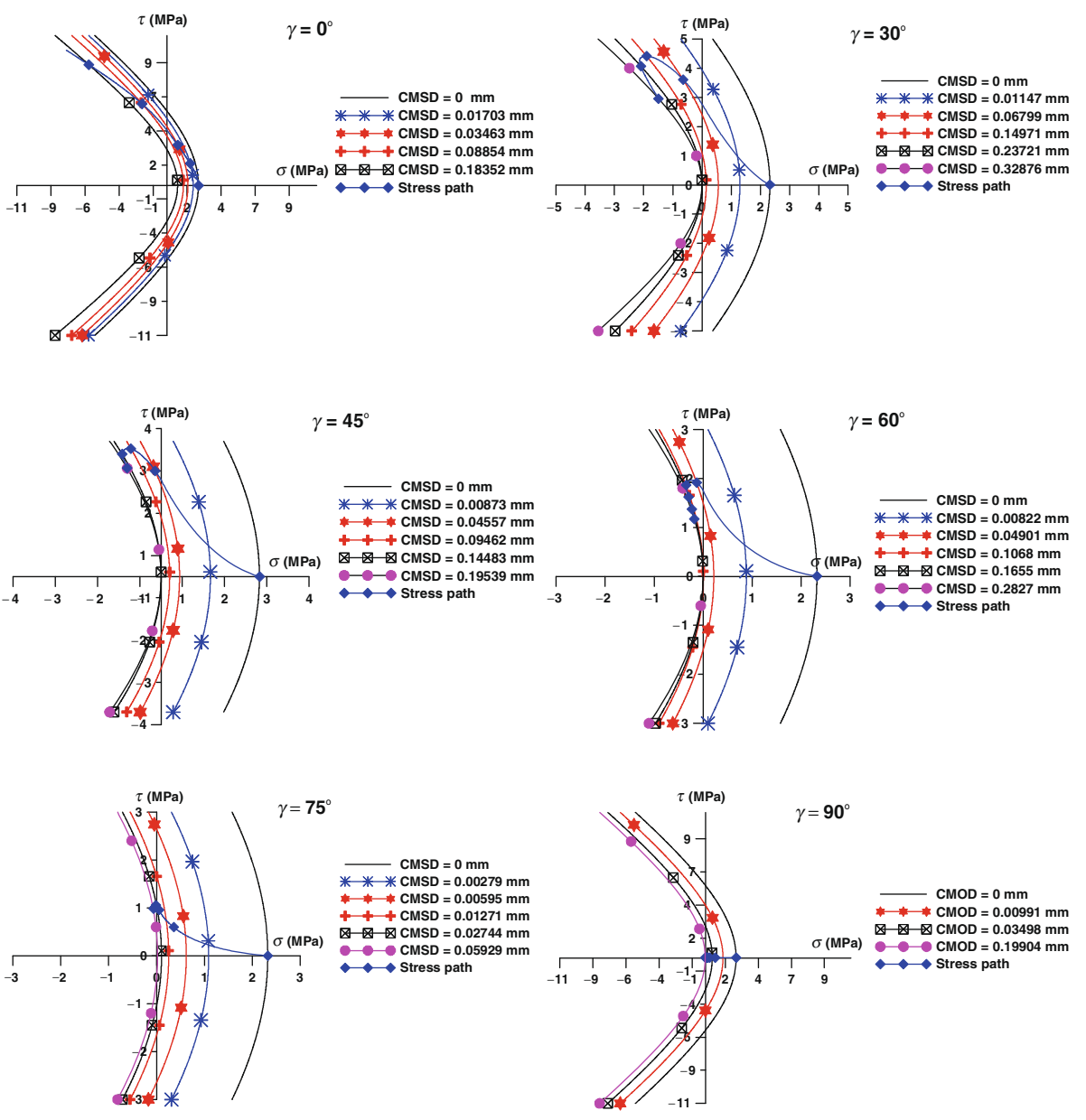

Figure 16. Stress paths for the different $\gamma$. 
the crack mouth sliding displacement (CMSD) increases. It can be seen that the peak value of $\tau$ is reached when $\chi=0$, i.e., when the vertex of the hyperbola is at the origin. This trend reflects the increasing importance of shear stresses on the cracking as the tensile stresses decrease, with the maximum shear stress occurring when the cohesive tensile stresses are zero, i.e., when the fracture process zone is fully developed. This is in accordance with the hypothesis made by Hassanzadeh (1990) in terms of crack propagation under shear. Also, we can see that, according to the model, cracking can occur in pure mode II only when shear forces are imposed along with high compressive stresses normal to the crack faces (figure 13). In general, it appears that the model can reproduce the characteristic trends of cracking dominated by shear stresses.

\section{Conclusions}

In this paper, a cohesive model for mixed mode fracture is presented and used in the simulations of tests of different sizes of geometrically-similar three-point bend concrete specimens with mid-span and eccentric notches. It is shown that mode I fracture dominates the behaviour even though the cracking is non-planar and the mode II energy dissipation component is negligible. Therefore, as already published in previous works (García-Álvarez 1997; Jenq \& Shah 1988; García-Álvarez et al 1998, 2002), non-planar crack does not implies mixed-mode fracture. The parameters obtained for a high strength concrete reflect its more brittle nature when compared with a normal concrete.

The model can also reproduce the general trends seen in Hassanzadeh's tests, where cracking is dominated by shear. An interesting result observed from stress paths obtained in the corresponding analysis is that the importance of shear on the cracking increases when the tensile stresses decrease, reaching a maximum when the cohesive stresses are zero, i.e., when the fracture process zone has fully developed.

\section{References}

Bocca P, Carpinteri A, Valente S 1990 Size effects in the mixed mode crack propagation: Softening and snap-back analysis. Eng. Fracture Mech. 35: 159-170

Bocca P, Carpinteri A, Valente S 1991 Mixed mode fracture of concrete. Int. J. Solids Struct. 27: 1139-1153

Carol I, Rizzi E, Willam K J (1994) A unified description of elastic degradation and damage based on a loading surface. Int. J. Solids Struct. 31: 2835-2865

Carol I, Prat P C, López C M 1997 A normal/shear cracking model. Application to discrete crack analysis. J. Eng. Mech. ASCE 123: 765-773

Carol I, López C M, Roa O 2001 Micromechanical analysis of quasi-brittle materials using fracture-based interface elements. Int. J. Numer. Meth. Eng. 52: 193-215

Carpinteri A, Valente S, Bocca P 1989 Mixed mode cohesive crack propagation. In: K Salama, K Ravi-Chandar, D M R Taplin, P Rama Rao (eds) Advances in fracture research (7th International Conference on Fracture), Pergamon. p. 2243-2257

Crisfield M A 1994 Nonlinear finite element analysis of solids and structures (New York, USA: John Wiley \& Sons Inc.)

di Prisco M, Ferrara L, Meftah F, Pamin J, de Borst R, Mazars J, Reynouard J M 2000 Mixed mode fracture in plain and reinforced concrete: some results on benchmark tests. Int. J. Fract. 103: 127-148

García-Álvarez V O 1997 Study of mixed-mode fracture in quasi-brittle materials (in Spanish). Doctoral thesis, Barcelona: School of Civil Engineering, Universitat Politècnica de Catalunya, Spain

García-Álvarez V O, Carol I, Gettu, R 1994 Numerical simulation of fracture in concrete using joint elements. Anales de Mecánica de Fractura 11: 75-80 
García-Álvarez V O, Gettu R, Carol I 1998 On non-planar fracture in concrete. In: H Hihashi, K Rokugo (eds) Fracture Mechanics of concrete structures (Proc. Third Intnl. Conf., FRAMCOS-3). Germany: AEDIFICATIO Publishers, Freiburg, vol. 1, p. 749-759

García-Álvarez V O, Gettu R, Carol I 2000 Numerical analysis of mixed mode fracture in concrete using interface elements. In: E Oñate, G Bugeda, B Suárez (eds) Proc. European Congress on Computational Methods in Applied Sciences and Engineering (ECCOMAS 2000). CIMNE. 20 pages.

Gens A, Carol I, Alonso E E 1988 An interface element formulation for the analysis of soil-reinforcement interaction. Comput. Geotech. 7: 133-151

Gerstle W H, Xie M 1992 FEM modelling of fictitious crack propagation in concrete. J. Eng. Mech. ASCE 118: 416-434

Gettu R, Shah S P 1994 Fracture mechanics and high strength concrete. In: S P Shah, S H Ahmad (eds) High performance concretes and applications. London, UK: Edward Arnold, p. 161-212

Gettu R, García-Álvarez V O, Aguado A 1998 Effect of aging on the fracture characteristics and brittleness of a high-strength concrete. Cem. Concr. Res. 28: 349-355

Hassanzadeh M 1990 Behaviour of fracture process zones in concrete influenced by simultaneously applied normal and shear displacements. Eng. Fract. Mech. 35: 845-853

Hassanzadeh M 1992 Determination of fracture zone properties in mixed mode I and II. Doctoral Thesis, Lund: Lund Institute of Technology, Sweden

Jenq Y S and Shah S P 1988 Mixed-mode fracture of concrete. Int. J. Fract. 38: 123-142

López C M 1999 Análisis microestructural de la fractura del hormigón utilizando elementos finitos tipo junta. Aplicación a diferentes hormigones (in Spanish). Doctoral Thesis, Barcelona: School of Civil Engineering, Universitat Politècnica de Catalunya, Spain

Mariani S, Perego U 2003 Extended finite element method for quasi-brittle fracture. Int. J. Numer. Meth. Eng. 58: 103-126

Ngo D, Scordelis A 1967 Finite element analysis of reinforced concrete beams. J. Am. Concr. Inst. 64: $152-163$

Olofsson T, Ohlsoon U, Klisinski M 1995 A simple fracture mechanics model for mixed-mode failure in concrete. In: F Wittmann (ed) Fracture mechanics of concrete structures (Proc. Second Intnl. Conf., FRAMCOS-2). Freiburg, Germany: AEDIFICATIO Publishers, p. 473-482

Rots J G 1988 Computational modelling of concrete fracture. Doctoral Thesis, Delft: Delft University of Technology, The Netherlands

Rots J G, Blaauwendraad J 1989 Crack models for concrete: Discrete or smeared? Fixed, multidirectional or rotating? Heron 34

Schellekens J C J 1990 Interface elements in finite element analysis. Report 25-2-90-5-17. Delft: Delft University of Technology, The Netherlands

Swartz S E, Lu L W, Tang L D, Refai T M E 1988 Mode II fracture-parameter estimates for concrete from beam specimens. Expt. Mech. 28: 146-153

Willam K J 1984 Experimental and computational aspects of concrete fracture. In: F Damjanić, H Hinton, N Bićanić, V Simović (eds) Computer aided analysis and design of concrete structures. Pineridge Press. p. $33-70$ 